\title{
LEAVING NO ONE BEHIND
}

\section{Exploring the experiences of adolescents in humanitarian settings}

\author{
Nicola Jones, Kate Pincock and Bassam Abu Hamad
}

Since arriving in Jordan in 2012 as a refugee from Daraa, Syria at the age of 12, Jana's life has not been easy. She lives in Azraq, a sprawling refugee camp situated in the middle of an inhospitable desert approximately 100 kilometres from Jordan's capital city, Amman.

Jana's family were unsure how to register her at school when they first arrived and they suffered from financial difficulties, so it was only after a year that she was able to resume her education as a Grade 6 student. She also experienced a lot of harassment in the first camp, Zaatari, where they stayed.'There used to be people who opened the tent and entered it while we were in it ... I mean young men.' However, she has since moved to Azraq camp with her family where her brother was detained for violating the Jordanian labour laws and has found the situation to be better. 'Here, on the contrary nobody dares to do the same. In terms of safety and security,Azraq camp is better.'

However, from an education standpoint, the move was not positive and Jana grew increasingly frustrated with the poor quality of teaching. Accordingly, when her sister's new husband introduced her to his Jordanian friend, she saw an opportunity to try and change her life and leave the confines of the camp, and so, at the age of 15, Jana decided to get married. Her parents did not approve of the marriage, but Jana was determined that it was the right decision and it would help improve her circumstances.

I told them that I wanted to marry him because our life was not as I wanted it to be. We did not have the money to live a proper life. So I thought that if I got married my situation will improve.

Unfortunately, married life was not as Jana had imagined. 'I did not know what would happen after marriage. I did not know that I will be holding such a responsibility.' She felt that she 'lived as if I was a foreigner in that house'. Six months after the marriage Jana decided to get a divorce, but shortly after she had returned to her parents' home, she found out she was pregnant. 
Jana is now living with her family in the camp with her son, and every month she requests a permit to go out of the camp to visit her ex-husband to let him see his son. She loves her son very much but lives in constant fear that her ex-husband and his family will take him away from her: 'the only thing I fear is to lose my son.' Jana would like to go back to school and restart her education but feels it is impossible in the short term due to childcare responsibilities. 'It is not over for me yet, but the problem is my son. I cannot leave him.'

Jana is one of more than 70 million people globally who have been displaced by persecution, violence, conflict and human rights violations - an unprecedented number in the history of the world. Of these 70 million individuals, 41 million are internally displaced, and nearly 26 million are refugees; the remainder are asylum claimants (United Nations High Commissioner for Refugees (UNHCR), 2018). This means that 1 in every 108 people in the world is now displaced. And of these vast numbers of displaced people, almost half - an astonishing 31 million - are children and adolescents under the age of 18 . Of this total, 13 million are recognised refugees and 17 million have been internally displaced within their countries' borders. A further 1 million are asylum seekers (United Nations Department of Economic and Social Affairs (UN DESA), 2017).

As Jana's story shows, displacement causes enormous disruption to young people's development trajectories in multiple ways. It compromises their access to education, as schooling is difficult to set up quickly in camp settings (UNHCR, 2018), and schools in host communities are often unable to cope with an influx of new students (Wanjiru, 2018; Jones et al., 2019b). Where there are few opportunities for household income generation by parents, many displaced adolescents in the global South enter work, often under dangerous or exploitative conditions (Evans et al., 2013; Gercama et al., 2018; Guglielmi et al., 2019; Jones et al., 2019b). Jana’s experiences also emphasise the way that gender shapes the experience of adolescence in diverse humanitarian contexts. In pursuit of financial stability and protection, girls may marry at an earlier age than they might have otherwise, but many girls will have little say as to when or to whom (De Jong et al., 2017; Jones et al., 2019b). Trauma - whether experienced during forced migration and/or in camps and settlements - exacerbates the emotional upheaval that adolescents are already experiencing as a result of bodily changes, placing young people at risk of poor mental health for years to come (Jabbar and Zaza, 2014; Hassan et al., 2016; Khan et al., 2018; Wanjiru, 2018).

Jana's story also emphasises the agency of adolescents in the face of these challenges. Far from being passive victims of trauma, violence and exploitation, adolescents find ways to navigate the structural constraints that are generated or amplified by displacement. As Jana's experience illustrates, these challenges not only affect adolescents as individuals but also reshape their relationships with their families, their peers and their communities. Attending to adolescents' capabilities does not mean downplaying or depoliticising the injustices of displacement, for which literatures on both refugee and young people's agency have rightly been critiqued (Evans et al., 2013; Easton-Calabria and Omata, 2018). Rather, this book seeks 
to directly connect and contextualise adolescents' experiences in relation to the broader social and political processes that shape their opportunities and choices.

This book arrives at a timely juncture for such a venture. The Sustainable Development Agenda 2030 to 'Leave No One Behind' emphasizes the need to ensure that the structural barriers that prevent the most marginalised people from participating in and benefiting from development investments, with the Sustainable Development Goals (SDGs) specifically outlining key indicators relating to youth, gender and more recently displacement. Alongside this, growing attention to the protracted nature of humanitarian crises and the attendant challenges for adolescents has led to increasing interest to the development of collective, long-term solutions to mass displacement. In 2018 alone, 13.6 million people were newly displaced, but the numbers of people classed as being in protracted displacement when a population of more than 25,000 people has spent more than five consecutive years in exile - also increased, from 66 per cent of refugees in 2017 to 78 per cent in 2018 (UN DESA, 2017). Change is urgently needed.

\section{Addressing knowledge gaps}

This volume addresses a number of key knowledge gaps with regard to young people's experiences of displacement. In this section we map out these central thematic domains, before turning to a discussion of the book's research methodology and an overview of each chapter.

\section{Age and gender}

With some noted exceptions, the majority of research at the intersection of young people and forced migration overlooks the particular experiences of adolescents in contexts of displacement in favour of a focus on children or older youths (Ball and Moselle, 2016). Yet focusing on adolescence is important because during this life stage, individuals undergo major biological and cognitive changes that affect their social position as adults (Patton et al., 2012; Viner et al., 2015). These social transitions can lead to unequal opportunities and outcomes. Whilst these will vary across contexts, it can generally be observed that the life-worlds of girls often become even smaller due to restrictive norms and expectations for adult women (Watson, 2015). Adolescence (10-19 years) is also increasingly seen as a key window for fostering positive development trajectories for all young people (Sheehan et al., 2017). In humanitarian settings, structural concerns such as poverty and insecurity present major challenges for ensuring these positive trajectories. Given the enormous numbers of people who are displaced, it is essential to develop a better understanding of how young people encounter displacement and what works to improve their outcomes during this critical life phase.

In contexts of displacement, we know that certain risks are amplified for adolescent girls (UNESCO, 2019). Sexual and gender-based violence is prevalent in humanitarian contexts but is usually under-reported, and formal institutions have limited capacity to prevent rape and harassment in such settings (Hynes and Cordozo, 2000; Hossain et al., 2014; Odwe et al., 2018). Agencies may also misunderstand the 
risks perceived by girls themselves (Williams et al., 2018). Driven by concerns about the safety of girls and their protection needs, families often limit girls' mobility, and their participation in social events may be even further discouraged (De Jong et al., 2017; Jones et al., 2019c). Efforts to keep girls safe can negatively affect their bodily integrity and psychosocial wellbeing, with an increase in child marriage - and thus early motherhood - seen across contexts of displacement, typically driven by a lack of alternative options for socioeconomic security, and poor provision of sexual and reproductive health services and information (Guglielmi et al., 2019; Jones et al., 2019c). These efforts to protect girls often inadvertently end up curtailing girls' agency and capabilities.

Displaced adolescent boys face challenges of a different kind. While girls are more likely to be confined to the home, boys may be expected to work in unsafe jobs to support their families (Evans et al., 2013), leading them to miss out on education. A lack of quality schooling can be a factor in this, as can violent schooling environments - with boys at greater risk of violence from teachers and peers than girls (Jones et al., 2019a). These experiences result in poor psychosocial outcomes for many adolescent boys (Jabbar and Zaza, 2014; Hassan et al., 2016). Unemployment and disenfranchisement - which are major issues for adolescent boys and young men in contexts of displacement because they disrupt transitions to masculine adulthood - are also linked to their recruitment into violent nationalist and other political movements (Mikhael and Norman, 2018). Conflict-affected populations are also known to be at risk for substance abuse (Ezard, 2012), yet most interventions focus on adults despite increasing recognition that adolescent boys may be particularly vulnerable to drug and alcohol use (Greene and Kane, 2020).

Despite widespread recognition of the importance of age and gender for international development, research has also not engaged substantively with the gendered dimensions of adolescents' experiences within humanitarian settings. Where gender is acknowledged as a factor shaping the experiences of young displaced people, research has tended to focus on young men and boys, traditionally treated as possible ex-combatants and as potential future threats to security (Hart, 2008) and thus a source of concern. When young women are considered, it is generally in relation to their vulnerability (particularly to sexual violence) rather than a focus on their capabilities (Boyden and de Berry, 2004). Positioning displaced young women simply as 'at risk' and young men as 'a risk to others' as a starting point for programming not only obscures the structural determinants of vulnerabilities but also undermines young people's capacity for agency (Evans et al., 2013). Moving beyond reductive framings of gender and youth by challenging the assumptions that underpin them is a key contribution of this book, with all chapters directly engaging with young people's own perspectives and experiences.

\section{Education and opportunity}

Research at the intersection of humanitarianism and adolescence has a strong focus on education. SDG 4 seeks to ensure 'inclusive and equitable quality education and 
promote lifelong learning opportunities for all', and education was a key concern of the 2019 Global Refugee Forum, which brought together UN member states to discuss progress on efforts to include refugees in national education systems (2019c). Education is perceived to be protective of young people's further involvement in conflict (Smith, 2014) and seen as vital for improving their opportunities later in life (UNHCR, 2019b). Yet despite gradual improvements, statistics indicate the scale of the challenge of educating refugees; at secondary school level only 24 per cent of refugees are in education, compared to 84 per cent of non-refugees (UNHCR, 2019a). Very little data is available about internally displaced youth and educational access. We know that barriers to adolescent refugees' inclusion in schools include language and cultural differences, stigma, legal obstacles, 'hidden' costs such as uniform and examination fees and the need to work to support families taking priority (UNICEF, 2017).

Whilst integrating adolescent refugees into national education systems is an important step, we must also recognise that formal education in and of itself is not a panacea to poverty and conflict; restrictions on rights to work and discrimination still preclude access to decent work, even for refugees with qualifications (EastonCalabria and Omata, 2018). Student-centred learning which deliberately harnesses aspirations in the context of an unknowable future can, however, support adolescents in developing the flexibility and 'cognitive mobility' to cope with long-term uncertainty (Dryden-Peterson, 2017). From the perspective of gender justice, preserving the identities of girls as 'learners' through continued education can also help to protect them from child marriage and entry into work (Zwier-Marongedza, 2020). Human rights education (HRE) which integrates human rights into both content and delivery approaches also shows promise in promoting young refugees' participation and advocacy in their communities (Devonald et al., 2020). Although the United Nations Children's Fund (UNICEF) has called for the development of alternative learning methods and curricula that reflect the needs of young people in hosting countries (UNICEF, 2019), evidence gaps remain as to the impact and effectiveness of non-formal approaches for overcoming the challenges associated with the protracted, indeterminate exile that four out of five young displacees face. Several chapters, including those on Syrian refugees in Jordan and on Rohingya refugees in Bangladesh, contribute to knowledge on these dynamics.

\section{Internal displacement}

Equally underexplored are the complexities and challenges to young people presented by the varied nature of displacement, and we include here a chapter on IDP experiences in Ethiopia, a country with one of the highest numbers of new internally displaced persons (IDPs), that engages with these concerns. By considering not just refugees but also internally displaced persons, this book also contributes to the literature on internal displacement - a field in which there has been almost no engagement with the gendered experiences of adolescents. While 'refugee' is a legal category and refugees are protected under the 1951 Refugee Convention, 'IDP' is a 
descriptive category only; this means that the United Nations' High Commissioner for Refugees' (UNHCR) Guiding Principles on Internal Displacement are not legally binding. This lack of legal recognition for IDPs can constrain the response of international organisations, creating a gap in terms of which organisation(s) takes responsibility for assisting women and youth (Macklin, 2008). Internally displaced adolescents are not catered for in the same ways as refugees (Austin et al., 2008), for whom education, skills training and health care are funded by the international community.

\section{Peace and sustainability}

Agenda 2030 has been applauded for presenting a framework that recognises the role of conflict resolution and sustainability in work at the humanitarian-development nexus. Climate change and peace form the basis of SDGs 13 (taking urgent action on climate change) and 16 (peace, justice and strong institutions), though across the whole Agenda, sustainability and peace are seen as the foundation on which equitable development can build (Howe, 2019). From a UN (2015) perspective, 'there can be no sustainable development without peace and no peace without sustainable development'. The 'new way of working' within the UN system, which emphasises collaboration and partnership between humanitarian and development actors, also calls for interventions which where possible can contribute to these outcomes (UNOCHA, 2017). Several authors identify these connections in their contributed chapters. Climate change - and more specifically environmental injustice - has long been a significant driver of internal displacement in Ethiopia (Nygren and Wayessa, 2018). The impact of climate change on resources such as fertile land and water is also likely to increasingly present challenges for actualising refugee 'selfreliance' in contexts characterised by inequality (Ilcan et al., 2015). This underlines the link between peace and sustainability; as seen in Jordan (Combaz, 2019), tensions over resources may lead to further conflict with local communities. Young people's participation in peacebuilding is increasingly seen as essential for the successful rebuilding of community and society in post-conflict settings (UNMGCY, 2019). Understanding adolescents' own perspectives on conflict and displacement is key to the development of interventions that support roles they may play in peacebuilding (Bellino, 2017; Berents, 2018). Peace processes are underway in some of the countries explored in this book, including Ethiopia. Yet other contexts remain in protracted conflict, with little sight of resolution on the horizon, underlining the importance of also attending, as several chapters do, to what interventions are needed by young people to support the lives they are making for themselves in contexts of displacement (Agbiboa, 2015).

\section{Policy and programming}

It is imperative to understand more about adolescents in different contexts of displacement in order to maximise the impact of recent sea changes in international 
development and humanitarian aid policy. The Global Compact on Refugees seeks to bridge the aid-development nexus, moving beyond the immediate priorities of humanitarian assistance and finding ways to promote long-term solutions to displacement; however, as with the 1951 Refugee Convention, the Global Compact does not include internally displaced persons. In 2018, the United Nations High Commissioner for Refugees (UNHCR) also reiterated its commitment to mainstreaming age, gender and diversity through an updated policy, which explicitly addresses the inclusion, participation and empowerment of women and girls, and of children and youth more broadly. In light of this, the Global Compact indicator framework calls for data to be disaggregated by sex, age and diversity, but it recognises that this is not always available from all sources of monitoring, presenting challenges for ensuring that adolescents are included in the benefits that the Global Compact seeks to deliver (UNHCR, 2019b). The 2019 Global Refugee Forum - a key milestone in implementing the Global Compact - saw stakeholders, including states and international organisations, make pledges to implement better protection measures for women and girls, and for children and youth.

These moves reflect an appetite at policy level for ensuring that developmentinformed approaches to managing displacement do not further entrench inequalities based on age and gender. This is a key objective of the 2030 Sustainable Development Goals and the 'leave no one behind' agenda, which has drawn increasing attention to those who tend to be marginalised within existing development interventions. Yet as it stands, the 2030 Agenda for Sustainable Development has various shortcomings as a benchmark for designing policies and interventions that support displaced young people. It does not, for example, identify refugees and IDPs as specific populations requiring attention, despite the particular risks they face. Nor does it recognise the specific needs of stateless people, despite UNHCR acknowledging that they are among the most vulnerable people - politically, economically and socially. Given the numbers of displaced people globally and the particular marginalisation faced by young people who are displaced, it is essential that stakeholders consider how the SDGs can meet the needs of populations on the move, and particularly the most marginalised individuals/groups within those populations.

UNHCR and the International Organization for Migration (IOM) do not have an official mandate to report on SDG targets, but they have recognised ten indicators within six goals and targets as being especially relevant to refugee populations. This is an important starting point for more discussion about how to bring development and humanitarian agendas together to leave no one behind. Yet one of the major obstacles for effective programming is the lack of gender- and age-disaggregated data, which makes it difficult to know what is happening to women and girls who are displaced - and what is needed to support their capabilities. Given the challenges and risks documented within the existing literature around adolescent refugee girls' access to safe work (O'Neil et al., 2016) and to education (UNESCO, 2019), and their vulnerability to age-based violence, a gender- and age-specific lens for the planning, implementing and monitoring of the SDGs is essential to ensure that no one is left behind. 


\section{Aims of the book}

This book has three main aims. First, as emphasised earlier, it underlines the need to pay more attention to adolescents in contexts of displacement. The insights that contributors provide into the experiences of adolescents in such contexts not only shed light on the particular challenges facing refugee and displaced young people but also highlight their resilience and capabilities. In so doing, the book seeks to contribute to significant gaps in knowledge around adolescents' capabilities in six key areas: education; health and nutrition; freedom from violence and bodily integrity; psychosocial wellbeing; voice and agency; and economic empowerment. The relationship of these capabilities to broader global objectives, such as the Global Compact on Refugees and the SDGs, is emphasised.

The second aim is to identify themes that cut across divergent humanitarian contexts, whilst keeping sight of contextual nuances. A key innovation of this book is that it presents findings from displacement settings that are geographically and temporally diverse. The Middle East, Asia and Africa are all contexts in which there are very different refugee populations, with crises varying from acute to protracted, across countries. In Bangladesh, the Rohingya refugee population continues to grow, with over a million refugees fleeing from Myanmar since 2017. Ethiopia, which has long hosted refugees from East Africa and Somalia, has, since 2017, accommodated a huge upsurge in IDPs, with more than 3 million people displaced in the region due to political violence and climate change. In Rwanda, Congolese refugees make up the majority of camp residents, with some living in displacement for more than 20 years due to the ongoing nature of the conflict in the Democratic Republic of Congo (DRC). Jordan and Lebanon both host significant numbers of displaced Syrians as a result of the civil war in the country since 2011; Jordan also hosts more than 2 million stateless, long-term displaced Palestinians who have been in exile for generations. This makes for an interesting diversity of cases from which to learn about and contextualise adolescents' experiences.

Third, the book also identifies implications for programming with refugee and internally displaced adolescents. In contexts of displacement, international agencies such as UNHCR, IOM and UNRWA (the United Nations Relief and Works Agency for Palestine Refugees in the Near East) provide vital assistance, protection and basic services. The Global Compact on Refugees reflects increasing recognition that solutions to protracted displacement require longer-term thinking that goes beyond meeting immediate needs. This book makes an important contribution to that thinking, exploring what works to empower adolescents now, and in the future, as they transition into early adulthood. In practice, however, relationships between state governments are complex, and local and global politics often shape and even restrict responses to refugee needs and access to services. This is especially pertinent in the case of IDPs, for whom there are no international agencies mandated to provide assistance; governments are therefore the first line in providing assistance, despite any potential political tensions over internal displacement. 
In contexts such as Palestine, where displaced adolescents are often the children of adults who were initially displaced many years before, it is essential to address the longitudinal political and economic consequences for adolescents (Chatty, 2010). In Jordan, a new Compact was initiated in 2016 to enable Syrian refugees to access labour markets, though this has brought mixed results for young people's economic empowerment (Lenner and Turner, 2018) and has also faced some reversals as broader economic malaise in the country has increased. Contexts such as the Rohingya crisis in Bangladesh, where immediate demands for humanitarian assistance take precedence, present their own challenges for meeting UNHCR's mandate to mainstream Age, Gender and Diversity into its programming. This is because it is particularly difficult to disentangle the various causes and consequences of adolescents' marginalisation in such rapidly evolving contexts. Yet at the same time, risks to adolescent girls, in particular, are magnified under such conditions (McLean and Modi, 2016). And in Rwanda, ongoing humanitarian challenges for Congolese refugees continue to fly under the radar, with a lack of political will and funding potentially hindering the effective implementation of Age, Gender and Diversity policies.

Currently there is a general dearth of programming specifically for adolescents, and limited work that addresses both the challenges they face and their aspirations in contexts of displacement. However, our empirical findings do identify several areas of promising practice, the implications of which we return to in the concluding chapter of this book. The research on which the chapters in this book are based draws on a conceptual framework informed by a capabilities framework, which explores the conditions and resources necessary for young people to improve their lives (Sen, 2004; Nussbaum, 2011). In doing so, the contributors explore 'what works' when it comes to policy and programming for adolescents to support their capabilities, generating important implications for those working with young people in contexts of displacement. Examples of promising interventions highlighted in the book include the non-formal education and safe spaces of Makani initiative in Jordan, which has helped to expand access to learning, peer networks and referrals to protection and basic services for young people in refugee and host communities across Jordan; innovative non-formal educational pathways for married Rohingya girls in Cox's Bazaar, Bangladesh; and investments that have led to gains in health and education for adolescents in Gaza.

\section{Conceptual framework}

\section{The '3 Cs'}

Through this book, we advance the need to understand the experiences and outcomes of displaced adolescents by attending to three interconnected aspects of their lives. Known as the ' $3 \mathrm{Cs}$ ', these aspects are: adolescents' capabilities, the change strategies that exist, and the contexts in which adolescents are situated (GAGE 
consortium, 2019). All of these have a significant effect on adolescents' trajectories in contexts of forced migration and displacement, and many aspects are deeply gendered. This framework also attends to the role of structure and agency in shaping adolescent trajectories. An approach that accounts for these three dimensions - and the ways in which they intersect - is essential for tackling the challenge of developing effective interventions with displaced adolescents.

The first ' $\mathrm{C}$ ', capabilities, refers to the challenges that need to be overcome across six dimensions of adolescent wellbeing. Capabilities are one's capacity to achieve valued ways of 'doing and being' (Sen, 2004; Nussbaum, 2011). Within the research from which the chapters of this book draw, six 'capability domains' are identified, which make important contributions to adolescents' capacity to live a good life. These are: health and nutrition, education and learning, voice and agency, economic empowerment, bodily integrity and freedom from violence, and psychosocial wellbeing. Adolescence has an important impact on the development of capabilities across these domains due to both the intense physical changes that happen during puberty and the social roles afforded to boys and girls in their family and community (Patton et al., 2012; Steinberg, 2015; Viner et al., 2015). For girls, adolescence is typically a time when their options are reduced and their capabilities are restricted, necessitating a gendered lens for policy-makers and practitioners. In contexts of displacement, being able to expand one's capabilities may be further disrupted or complicated; for example, a lack of quality schooling in a camp - or fears over the safety of the journey to school - may constrain girls' capabilities in relation to education and learning.

The second ' $\mathrm{C}$ ', change strategies, refers to the policy and programming needed to improve outcomes in these domains. A growing body of evidence suggests the need for change strategies that involve actors at various levels, including families, schools, communities and service providers, coming together to find ways to support adolescents - and girls in particular, given the particular constraints they face - in achieving capabilities. In contexts of displacement, identifying effective change strategies is particularly complex, given the rapidly changing nature of many refugee situations and the stakeholders involved. Effective change strategies identified by previous research with relevance for refugee, IDP and stateless populations include: empowering adolescent girls to build on their strengths and develop voice and agency within safe spaces, engaging with boys and men to exercise positive masculinities, supporting families to support their daughters, promoting social norms change, and strengthening the services and systems that adolescents access or need (GAGE consortium, 2019).

The third ' $\mathrm{C}$ ' highlights the effects of context - at the local, national and international levels - on these strategies. An interplay of diverse contextual factors shapes adolescent girls' vulnerabilities and opportunities (Viner et al., 2015. While cultural, religious and social dynamics play an important role here, it is essential not to overlook how these dynamics interact with displacement, and associated factors such as conflict and humanitarian assistance. Families and communities are disrupted and often torn apart during displacement, and the political and social contexts they find 
themselves having to navigate may amplify or undermine existing discriminatory gender norms. Understanding these effects, and integrating this understanding into change strategies, is essential. The rapid implementation that often characterises humanitarian efforts can mean that actors overlook the ways in which local context might counteract or hamper attempts to deal with sensitive issues such as genderbased violence, undermining the impact of programming with young displaced women (McLean and Modi, 2016; Sommer et al., 2018).

\section{Theoretical frameworks}

Our attention to the role of context, capabilities and change strategies in shaping adolescents' experiences and outcomes is influenced by several key strands of thought with particular significance for adolescents in humanitarian settings. The first is the ecological approach, which emphasises the role of social location in adolescents' choices and options. The second is the notion of generationing, which attends to the socially constructed nature of age itself. The third is intersectionality a theory that has gained enormous traction in enabling us to recognise how structural marginalisation prevents some adolescents from thriving, even when choices are ostensibly available. Taken together, these paradigms help to illuminate the importance of balancing structure and agency in analysing adolescents' trajectories in humanitarian settings. These approaches also have complementary implications for how capabilities, change strategies and context are understood.

The central tenet of the ecological approach is that young people develop in a social context; parents, peers, teachers and a range of other actors are part of this social fabric, as are economic, political and social forces and structures (Bronfenbrenner, 1986). Kostelny (2006) suggests that an ecological approach can also help in understanding how best to support adolescents in terms of change strategies in post-conflict settings; psychosocial support to displaced children, for example, is best provided through holistic, culturally grounded, family- and community-based methods. In terms of capabilities, an ecological approach recognises that the social milieu and networks within which children are located will shape their voice, agency, bodily integrity, opportunities for work and education, access to health care and overall wellbeing. This includes collective capabilities, which refer to the activities necessary to help groups of people to work together towards shared goals of empowerment and capability expansion. At a structural and institutional level, there must be opportunities for collective agency to be exercised, enabling collective capabilities to be 'scaled up' in order to trigger broader transformation (Ibrahim, 2006). In humanitarian contexts, this means situating the experiences of individual adolescents in relation to the structural nature of marginalisation and disempowerment, especially when identifying change strategies, to ensure that these attend to the political and socioeconomic dynamics that constrain opportunities for displaced populations.

Next is the application of 'generationing' to contexts of displacement. In asserting the importance of adolescence as a life stage, we acknowledge that it constitutes 
a socially constructed category that varies across contexts. Attention to 'generations' re-situates age not just as a chronological fact but as a socially constructed context for young people's lives. It challenges the adult-centrism of much of existing development research, which often disregards the complex intergenerational dynamics in which young people engage with programming, instead treating them reductively as project beneficiaries (Huijsmans, 2016). This is despite the significant body of research in global childhood studies more broadly that draws attention to children and young people's agency within broader processes of development and change (Katz, 2004; Ansell, 2005; Tisdall and Punch, 2012). Huijsmans et al. (2014) point to the ways that development transforms the opportunity structures that shape young lives, including these intergenerational dynamics. In contexts of protracted displacement, a 'generationing' approach can provide insights into patterns of social reproduction which shape displaced adolescents' identities and relationship to the world around them. It is essential to note that in attending to these dynamics, we do not seek to unequivocally position older generations as bearers of problematic traditions and cultural norms. Where social reproduction is explored, it is with recognition that families and communities are all subject to the structural violence of displacement and that, as in any other context, they are often seeking to protect and support adolescents the best they can in the face of enormous challenges. Drawing on a 'generationing' approach, we attend to the impact of displacement on young people's place in the world and consequences for their capabilities. Looking at their collective capabilities means not just attending to the empowerment of individual girls to exercise agency but looking too at the networks of relationships that may rechannel power in ways that recalibrate patterns of gendered and aged inequality (Ansell, 2014). In thinking of change strategies, a 'generationing' approach is key to identifying both moments of disjuncture between older and younger cohorts, and opportunities that displacement may potentially bring to disrupt the reproduction of norms and shift adolescents' trajectories in new directions.

The third important paradigm shaping the framework of this book is intersectionality. As White (1996) so aptly showed, young people are not a homogenous group; various power dynamics characterise their interactions and shape their representation, participation and inclusion. An intersectional approach rejects the idea that a single category such as 'gender' or 'age' should be central to analysis, instead emphasising the ways in which inequalities that include gender and age - but also disability, socioeconomic status, rurality, citizenship and migration status - interact with and co-constitute each other to affect the capabilities of different adolescents (Hankivsky et al., 2012). Originating with black feminist scholars, intersectionality emphasises the ways in which different aspects of social identity converge to produce particular experiences of marginalisation (Hooks, 1981; Crenshaw, 1989). These structures and processes are dynamic, meaning that contexts shift across time and place (Crawshaw and Smith, 2009). An intersectional lens also draws attention to the fluidity with which displaced people may relate to categories in the first place (Hyndman, 2010; Ludwig, 2016). An intersectional approach to change strategies recognises that power and privilege differentials will mean that certain 
adolescents are likely to be 'left behind' if programming does not directly address the structural drivers of inequality. Adolescents' collective capabilities can be built by strengthening their individual knowledge and awareness of social justice issues and instigating social change to benefit those who are most marginalised (Kabeer and Sulaiman, 2015).

\section{Methods}

The chapters of this book all draw on findings from research undertaken as part of the Gender and Adolescence: Global Evidence (GAGE) longitudinal programme (2015-2024). GAGE is a mixed-methods, multi-country research programme that aims to understand the lives of adolescents in six low- and middle-income countries (LMICs), exploring 'what works' when it comes to policy and programming. The book focuses on findings from ongoing research in six contexts of displacement: Rwanda, Ethiopia, Jordan, Lebanon, Bangladesh and Palestine. In order to capture the multidimensionality that is embedded within the conceptual framework, and to engage with a broad range of actors over a number of years, the data presented here were generated using a variety of innovative methods, often in combination, which comprise the GAGE methodological toolkit. These include: quantitative surveys with younger (10-12 years) and older (15-17 years) adolescents and their caregivers, qualitative interviews with individuals and groups, and participatory research with especially vulnerable adolescents. Table 1.1 provides an overview of the sample in each research context.

\section{Ethics}

Driven by a commitment to equity and justice, all GAGE research is undertaken in line with principles of avoiding any harm, protecting the rights of adolescents, ensuring participation is voluntary and based on fully informed consent, and ensuring confidentiality. Participation was approved by caregivers for adolescents under the age of 18, and consent was given to participate in each research activity. Operationalising these principles means working in accordance with the United Nations Conventions on the Rights of the Child. However, the complexity and volatility of humanitarian contexts, and the vulnerabilities that they may create or reinforce for adolescents, means that particular care must be taken to uphold these principles in research in these settings (Berman et al., 2016).

Existing research indicates the value and importance of adolescents' participation in research which seeks to identify ways to improve conditions for young people (Cayemittes et al., 2014). Yet it is essential to recognise how relations of power might put adolescents at risk when they do participate. This requires a proper understanding of how the context itself may affect adolescents' capacity to participate in research both meaningfully and safely. Planning and consultation with local research partners and teams working in these contexts led to the design of a methodological toolkit which sought to mitigate any infringement of 
14 Nicola Jones et al.

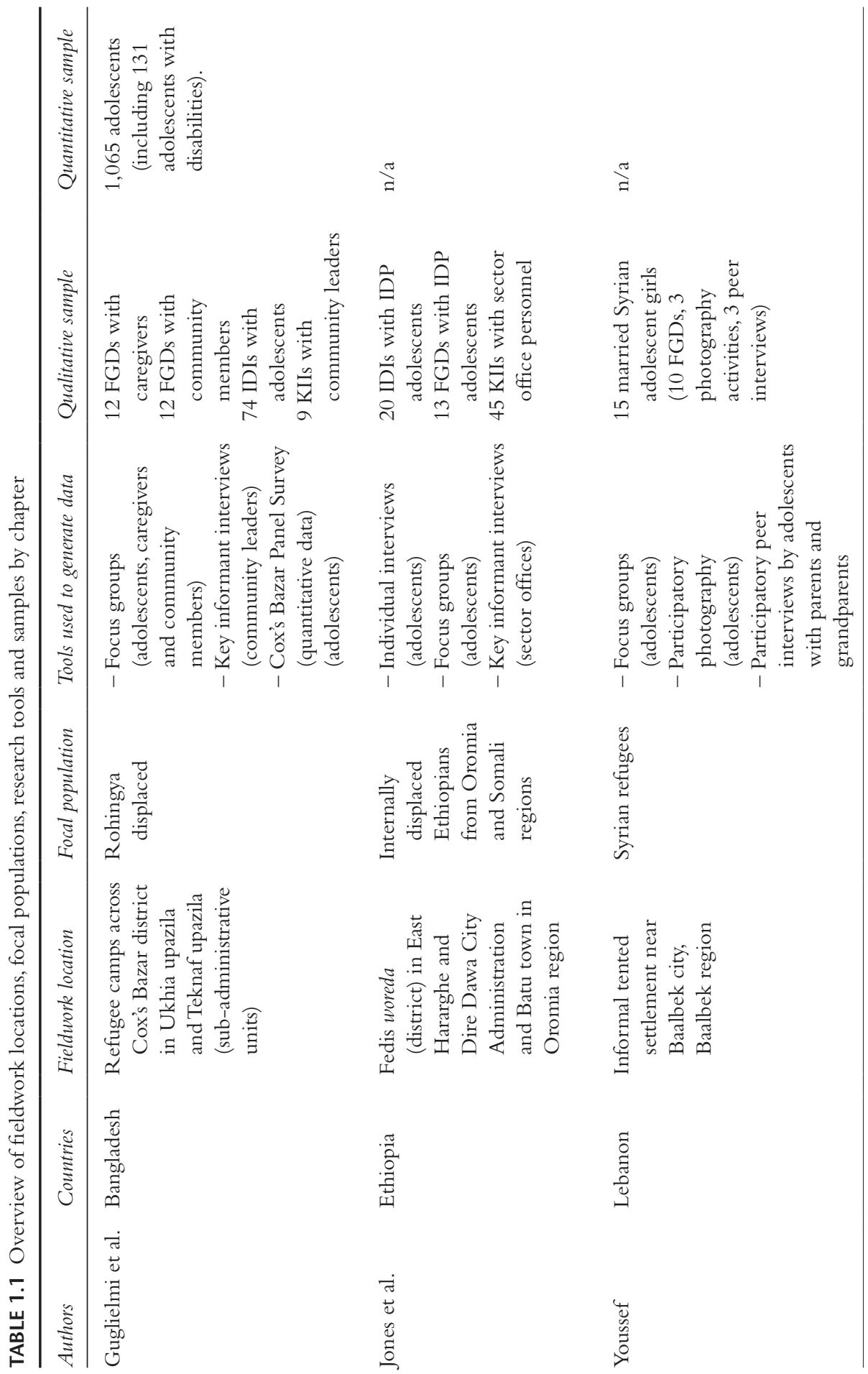




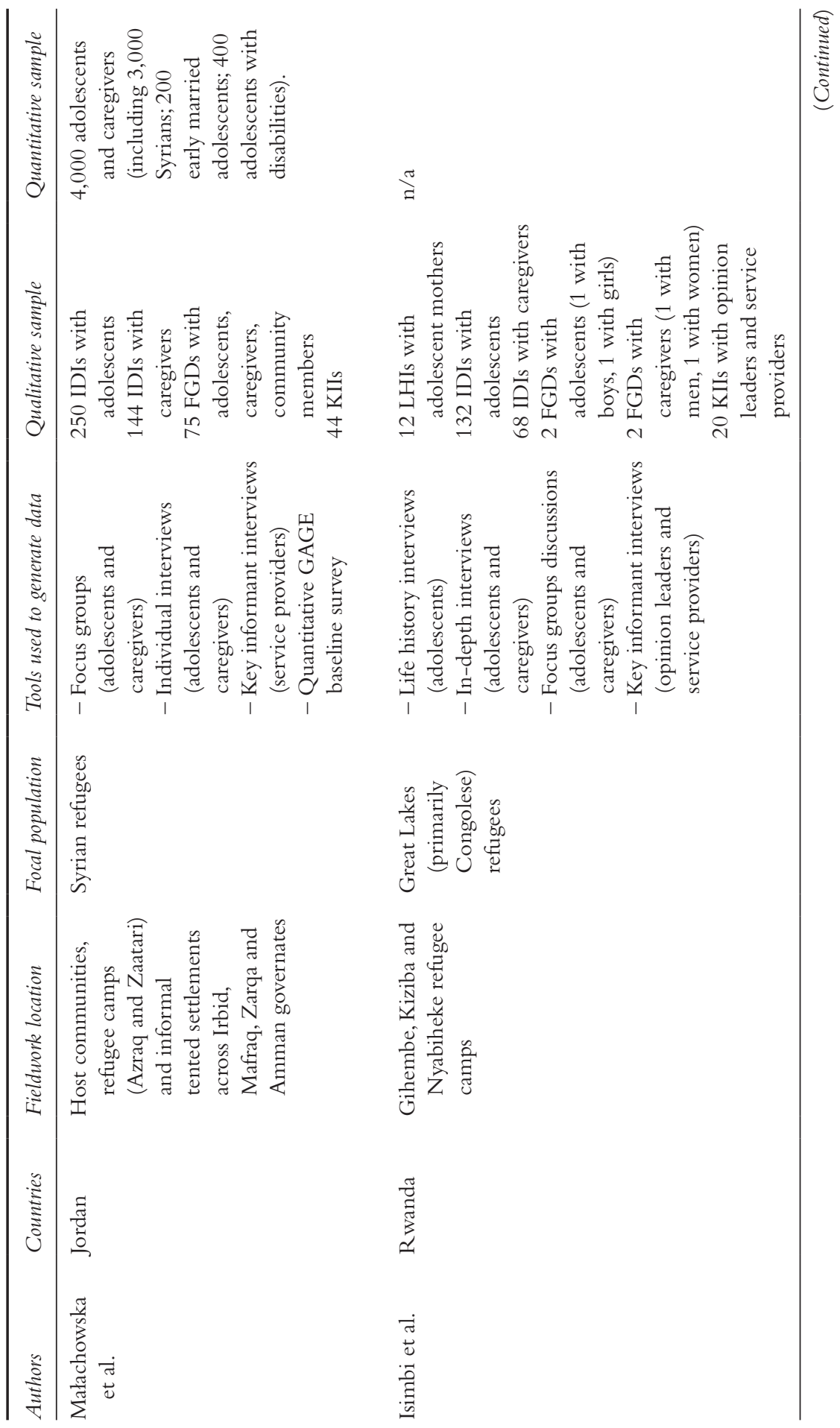


16 Nicola Jones et al.

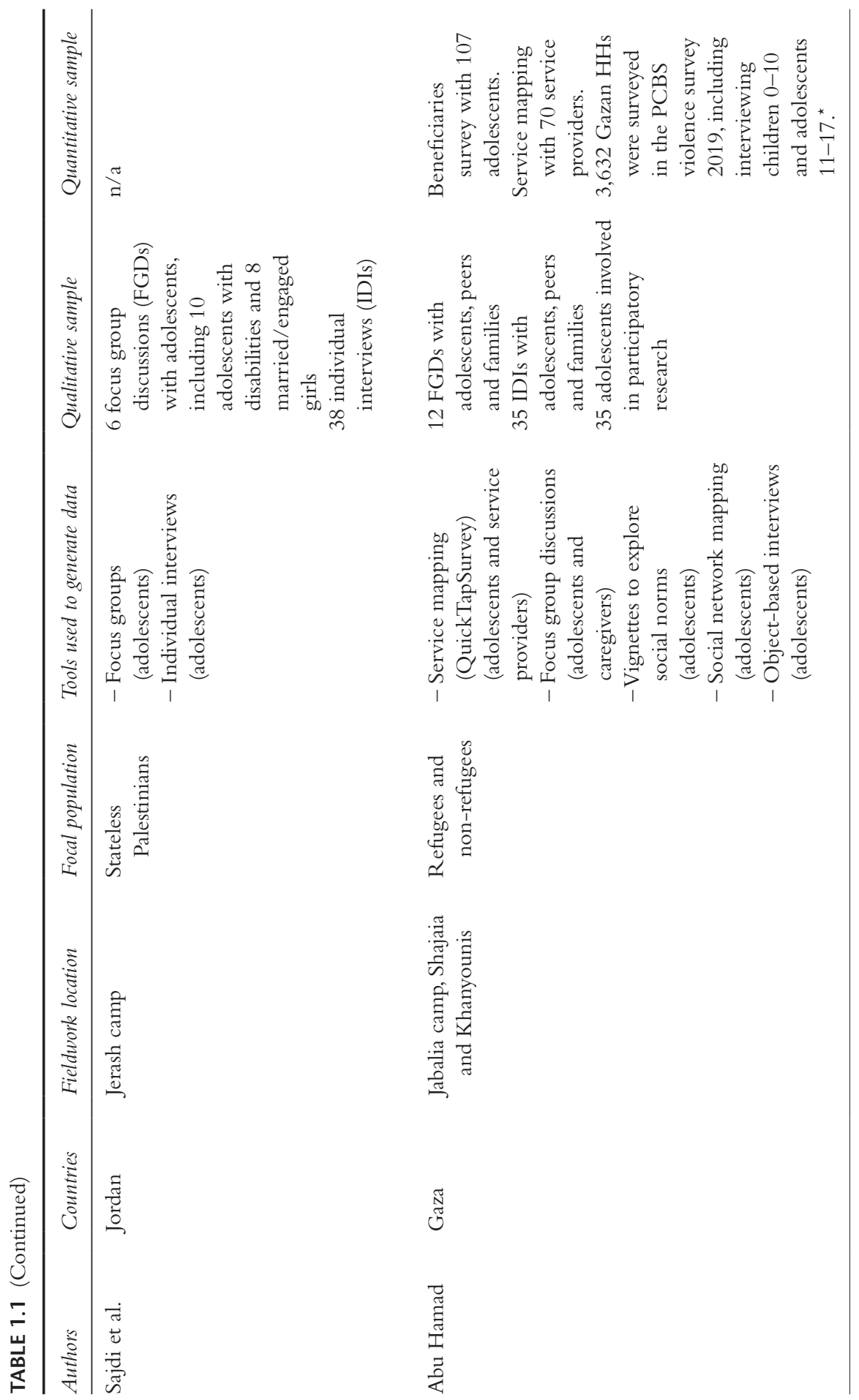




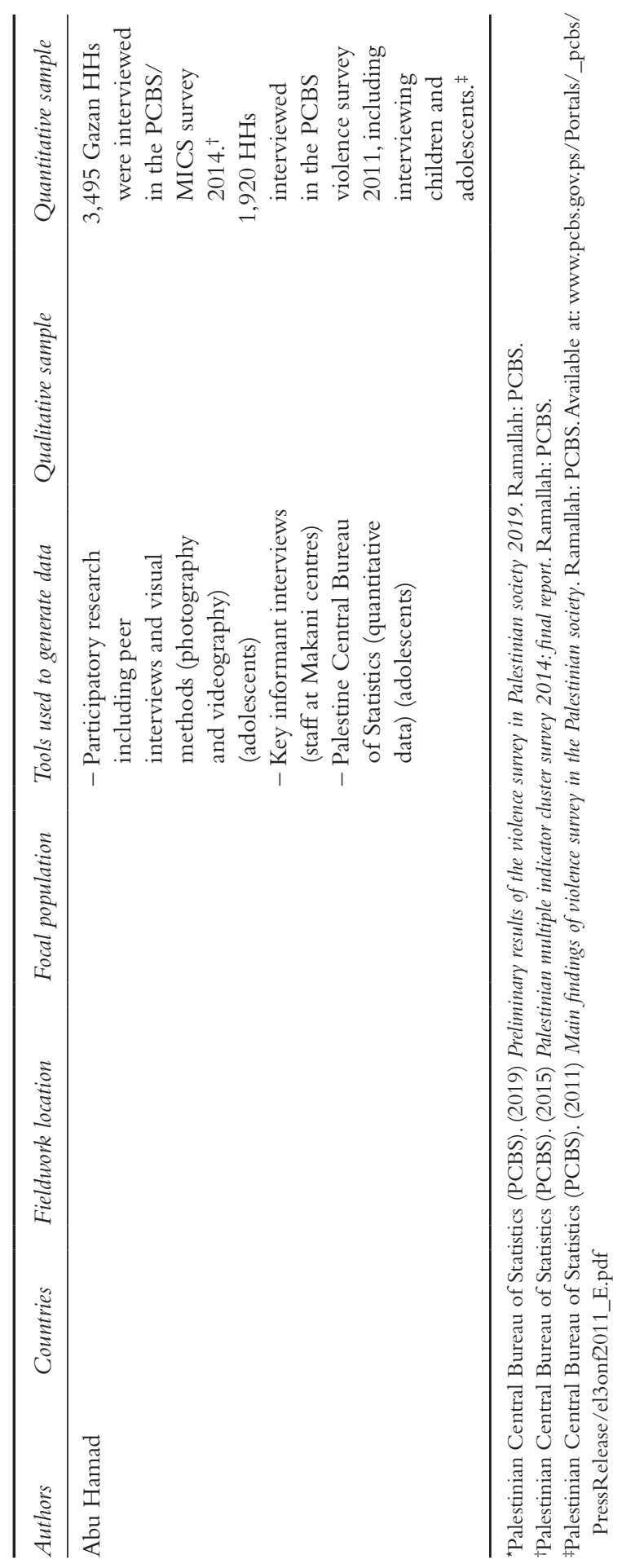


the commitments made by GAGE to equity and justice. All qualitative research received ethics approval from the Overseas Development Institute Research Ethics Committee, and all quantitative research received IRB approval from George Washington University. Furthermore, researchers in each country adhered to national ethics guidelines and secured approval from relevant national ethics boards. They also identified local government, non-government and UN partners to whom they could refer young people in need of child protection or mental health support, and they kept a detailed referral tracker.

\section{Qualitative and participatory methods}

Qualitative and participatory methods feature in all seven of the contributing chapters in this book. Our approach is influenced by the anthropology of childhood, and in particular what has come to be known as 'childhood studies' (Prout and James, 1990; Qvortrup et al., 1994). This is important to note because humanitarianism and anthropology often theorize and codify childhood in different ways, with a humanitarian legal perspective taking a universalising approach to notions of childhood and adulthood and an anthropological perspective emphasising the social construction of childhood in relation to context (Rosen, 2007). Borrowing from this latter lens, we focus on the social, political and economic forces which structure the lives of young people in humanitarian settings, including interventions to assist them. For example, the power dynamics which can lead well-intentioned development efforts with young people to manifest in 'solutions' that may be inappropriate undermine their agency and obscure solutions that may be more practical and realistic than those envisaged (Reynolds et al., 2006).

Participatory methods can provide a means to both investigate and address structural and relational marginalisation, and thus they form a cornerstone of the research with adolescents in humanitarian contexts presented here. By addressing power relations between researchers and participants, participatory research can enable representation and inclusion of groups whose voices and perspectives tend to be 'left behind' by research and practice around displacement and conflict. Participatory tools broaden opportunities for and modes of expression. Examples of these kinds of flexible participatory tools include 'My Favourite Things', in which young people are asked to think of an object that is important to them and, through this, reflect on and explore its significance in their lives. This tool can be adapted to the capacities of the adolescent and allows narratives to centre on what matters to them, making it flexible for use with adolescents with disabilities, as well as adolescents of different ages.

Recognising the importance of connection, family and peer relationships in displacement, other participatory tools have explored adolescents' social resources. These include the 'Friendship Circle', where adolescents come together with their peers and discuss the nature of their friendship together; and 'Community Mapping' and 'Social Network Hexagons' that are drawn by adolescents to explore with whom they interact and in what ways these interactions affect them. Participatory 
research has also been used in contexts of displacement to understand how adolescents' lives have changed over previous years, through the 'Most Significant Change' timeline. A 'Dragon's Den' exercise saw young people lead teams to come up with solutions to problems they had identified.

Innovative digital and virtual participatory tools were also used, engaging adolescents' perspectives and opinions in ways that were both thought-provoking and enjoyable. The 'QuickTapSurvey', a tablet-based tool, was used to investigate adolescents' experiences of key services and programmes. The 'Madam President' tool uses video excepts as a starting point to explore what happens when a female president comes to power. The PhotoVoice method was also used as a way for young people to document and reflect on their lived daily realities, with young people encouraged to take photographs of items that were significant to them. Through the 'SHOWeD' technique, they were then asked to describe what they had photographed, what was really happening in the picture, its relationship to their lives, its reason for existing and what could be done about it.

In recognition that adolescents' agency and capabilities are bound up in intergenerational relationships (Tisdall and Punch, 2012), across the country contexts, extensive in-depth interviews and focus group discussions were undertaken with adolescents, parents and grandparents. Key informant interviews were also conducted with community stakeholders, and various actors within government and community organisations. With adolescents, vignettes were used in groups to broach topics which participants might find uncomfortable to discuss in relation to their personal experiences. Small group discussions were also used to facilitate more focused (rather than exploratory) reflections. For discussing more sensitive topics with individual adolescents, the 'Body Mapping' exercise, in which adolescents draw a picture of a young person's body and reflect on what different parts symbolise, can facilitate discussions on emotional and psychosocial wellbeing, relationships, puberty, health and disability, and gender-based violence.

It is important from an ethical perspective that young people's involvement in research determine findings and can see the result of their contributions and that their communities participate in the research - especially when these communities have been affected by conflict (Berman et al., 2016). Accordingly, adolescents involved in the research actively contributed to sharing and presenting findings with their wider communities in various creative ways. Meetings were also held that included reflections from adults and community leaders about their experiences when they themselves were adolescents, using tools such as timeline exercises, a quiz for 'role models' and 'World Café' sessions.

\section{Quantitative methods}

GAGE uses three core quantitative instruments, with common as well as countryspecific questions and modules, with adolescents, parents and adults. Interviews were conducted with the primary caregiver of adolescents about their household and assets, amongst other topics. For the parents of younger adolescents (aged 10-12) 
these interviews are more expansive, including questions of parenting, attitudes and norms, mental health, financial status, exposure to violence and fertility. Surveys undertaken directly with adolescents were tailored to their age and local context and explored education, time allocation, paid work, health and nutrition, mental health, mobility, voice and agency, social inclusion, programme support, financial inclusion, economic empowerment, technology, marriage and relationships, sexual and reproductive health, and violence. In undertaking research with both adolescents and caregivers, it was possible to look at both parental influence on adolescent trajectories and the intergenerational transmission of, for example, mental health, violence and social norms. Including a quantitative element to the research has been key to developing large-scale datasets on which robust analysis can be taken and triangulated with findings from qualitative and participatory work.

We include three mixed-methods chapters in this book, each of which take different approaches to integrating qualitative and quantitative data (Abu Hamad and Guglielmi et al). The chapter by Abu Hamad presents a secondary analysis of data from the Palestinian Central Bureau of Statistics, focusing on surveys from 2011, 2015 and 2019 on adolescents' experiences of violence. These data are used to contextualise detailed qualitative and participatory GAGE research findings with adolescents in Gaza. The chapter by Guglielmi et al. presents findings from a quantitative survey nested within the 2019 Cox's Bazaar Panel Survey, which they analyse to identify the impact of access to educational tuition or materials on educational outcomes for Rohingya adolescents and to complement insights from qualitative data on barriers to education and learning. The chapter by Małachowska et al. draws on findings on educational outcomes, aspirations and access from the GAGE baseline survey undertaken in four governates of Jordan in order to corroborate the qualitative data presented.

\section{Overview of chapters}

The empirical chapters of this book follow a chronological order, starting with the most recent humanitarian crisis (Rohingya) refugees in Bangladesh and ending with the most protracted (Gaza). In the conclusion, we reflect on the relationship between the length of emergencies, how international funding and attention shifts over time, and the challenges facing adolescents as situations change. Prior to this concluding chapter, we include in Chapter 9 a discussion of research with adolescents in humanitarian contexts as to their experiences during the first year of the Covid-19 pandemic.

The first empirical chapter of this book by Guglielmi et al. turns to the experiences of young Rohingya refugees in Bangladesh, which in 2020 was the fastest growing refugee population in the world. Close to three years into mass displacement, a long-term solution for the stateless and displaced Rohingya population is lacking; but policy actors dispute necessary conditions for repatriation in Myanmar or potential relocation within Bangladesh, and adolescent Rohingya refugees are sidelined and at risk of becoming a lost generation without access to widespread 
formal - or non-formal - education, limited vocational training opportunities and an absence of livelihoods. The authors explore the various cultural and structural constraints, including legal status, age and gender, which limit educational and economic opportunities for adolescents in Cox's Bazar and propose opportunities for interventions which can help to improve their outcomes.

The next chapter by Jones et al. addresses the challenges presented by internal displacement, focusing on Ethiopia, where more people were newly displaced in late 2017 and 2018 than anywhere else globally during the same period. The chapter explores the economic and psychosocial vulnerabilities of internally displaced adolescents in Ethiopia, focusing on gender, age and geographical similarities and differences in experiences. The authors draw attention to gaps in the 'developmenthumanitarian-peace nexus' that increasingly dominates thinking on the types of episodic and protracted displacement seen in LMICs such as Ethiopia, showing that a lack of formal support by government actors creates economic vulnerability for adolescents, which is exacerbated by the stigma of being an IDP. Beyond initial humanitarian responses, greater access to social protection and assistance for IDPs is vital to prevent further social fragmentation between IDPs and host communities.

The third empirical chapter of this book by Youssef looks at the psychosocial wellbeing of Syrian refugee girls in Lebanon, a country which hosts the largest number of refugees per capita in the world, amidst a protracted political and economic crisis. Drawing on data from research with married Syrian refugee girls, the author explores the role of conflict, marginality and gender in shaping their psychosocial wellbeing. Loss of educational opportunities and the economic precarity presented by displacement to Lebanon drive both girls' entry into the labour market and their resignation to the possibility of being pressured into marriage. Whilst both unmarried and married girls report anxiety and stress due to discrimination and the burden of helping to care for their families, the author shows that married girls indicate high levels of psychosocial distress, compounded by their experiences of social isolation.

The fourth empirical chapter by Małachowska et al. engages with the educational participation and outcomes of Syrian adolescents in Jordan. Although the Government of Jordan has opened its school system to include Syrian children and adolescents - and donors and NGOs have invested heavily in scaling up nonformal learning pathways - enrolment rates remain low, especially for secondary and tertiary education. Learning outcomes for those adolescents who are in school are also unsatisfactory, especially for boys. This chapter explores the intersecting barriers to quality education facing boys and girls in three settings in Jordan: host communities, informal tented settlements and refugee camps. The authors challenge existing representations of girls and boys as passive by centring the perspectives and experiences of Syrian adolescents living in Jordan to explore how they seek to navigate and overcome these gendered and socio-demographic vulnerabilities and ask what is needed to improve educational outcomes.

The fifth empirical chapter by Isimbi et al. turns to refugee camps in Rwanda, analysing the way that social norms intersect with age, gender and refugee status to 
affect the wellbeing of Congolese adolescent girls. Despite laws in Rwanda which state that sex with a minor is a criminal offence, restrictive gender norms within Congolese refugee communities mean that vulnerable girls are then stigmatised and blamed for pregnancy, even when it is a result of sexual violence. The authors show that stigma is compounded by a lack of age- and gender-sensitive sexual and reproductive health services for girls in refugee camps and a lack of knowledge about laws that protect victims of sexual violence in Rwanda, including refugees. This negatively affects adolescent girls' psychosocial wellbeing, and both their access to and aspirations around education, despite their hopes for a better future.

The sixth empirical chapter by Sajdi et al. engages with the experiences of stateless Palestinian adolescents living in Jerash camp in Jordan, which was established in 1968 for refugees from the 1967 Arab-Israeli War. Over 50 years later, the camp is one of the poorest in Jordan due to livelihood opportunities being restricted for those without Jordanian nationality who live there. Seeking to understand high rates of attrition from formal education, this chapter centres the perspectives of stateless adolescents as they navigate schooling within an economically restrictive and highly gendered social context. Violence against Palestinian boys in schools is a key driver of their early exit from education and entry into the labour market; in contrast, for adolescent girls, mobility is increasingly restricted as they get older, with marriage seen as a form of protection from violence. Taken together, the authors show how these dynamics result in lowered aspirations amongst refugee adolescents.

The last empirical chapter by Abu Hamad focuses on the heightened risk of adolescents facing Palestinian adolescents who continue to live in politically turbulent Gaza. Whilst existing literature on violence in Palestine focuses on political violence, the impact of violence on adolescents - especially girls - is largely overlooked. This chapter thus focuses on the role of gender norms in shaping experiences of violence, contributing to better understanding of how to protect bodily integrity in conflict-affected areas. The author finds that other than treating adolescents for physical injuries and providing psychosocial first aid during episodes of conflict, there is limited formal support available to adolescents who have experienced violence; moreover, a culture of silence normalises violence.

A penultimate chapter closes the empirical contributions of the book and underlines the arguments set forward in other chapters as to the urgent need for attention to adolescents within interventions at the humanitarian-developmentpeace nexus. This chapter presents emerging evidence of the impact of Covid-19 on young people across several contexts explored in the book. We show that the pandemic and subsequent government responses have dramatically impacted adolescents in humanitarian contexts, constraining their access to education, health care, nutrition and recreational opportunities, in addition to increasing stress level and accentuating violence. Being a refugee, internally displaced or stateless exacerbates adolescents' social exclusion, poverty and vulnerability under Covid-19. Indeed, the experiences of displaced adolescents under Covid-19 demonstrate the depth and breadth of existing inequalities in social protection, access to health 
care, psychosocial services and education, emphasizing the need for work at the humanitarian-development-peace nexus to prioritise age- and gender-responsive research, policies and programming. Drawing on these findings, in our concluding chapter we present a number of recommendations for priority actions to address these vulnerabilities and promote adolescent resilience and wellbeing.

\section{References}

Agbiboa, D. E. (2015) Youth as tactical agents of peacebuilding and development in the Sahel. Journal of Peacebuilding \& Development 10(3): 30-45. DOI: 10.1080/15423166.20 15.1082927

Ansell, N. (2005) Children, youth and development. London; New York: Routledge.

Ansell, N. (2014) Generationing development: a commentary. European Journal of Development Research 26(2): 283-291.

Austin, J., Guy, S., Lee-Jones, L., McGinn, J., and Schlecht, J. (2008) Reproductive health: a right for refugees and internally displaced persons. Reproductive Health Matters 16(31): $10-21$.

Ball, J., and Moselle, S. (2016) Forced migrant youth's identity development and agency in resettlement decision-making: liminal life on the Myanmar-Thailand border. Migration, Mobility, \& Displacement 2(2): 110-125. https://doi.org/10.18357/mmd22201616157

Bellino, M. J. (2017) Youth in postwar Guatemala: education and civic identity in transition. New Brunswick, NJ: Rutgers University Press.

Berents, H. (2018) Young people and everyday peace: exclusion, insecurity and peacebuilding in Colombia. London: Routledge.

Berman, G., Hart, J., O’Mathúna, D., Mattellone, E., Potts, A., O’Kane, C., Shusterman, J., and Tanner, T. (2016) What we know about ethical research involving children in humanitarian settings: an overview of principles, the literature and case studies. Innocenti Working Paper No. 2016-18. Florence: UNICEF Office of Research.

Boyden, J., and de Berry, J. (2004) Children and youth on the front line: ethnography, armed conflict and displacement. Oxford: Berghahn Books.

Bronfenbrenner, U. (1986) Ecology of the family as a context for human development: research perspectives. Developmental Psychology 22(6): 723-742. Available at: https://psycnet.apa.org/doi/10.1037/0012-1649.22.6.723

Cayemittes, M., Hatløy, A., Lunde, H., Pedersen, J., Sommerfelt, T., and Spraos, H. (2014) Child fosterage and domestic work. Oslo: FAFO Research Foundation.

Chatty, D. (2010) Palestinian refugee youth: agency and aspiration. Refugee Survey Quarterly 28(2-3): 318-338. https://doi.org/10.1093/rsq/hdp043

Combaz, E. (2019) Jordan's environmental policies and engagement on climate change. K4D Helpdesk Report. Available at: https://assets.publishing.service.gov.uk/media/5d30a131ed 915d2ff003b781/619_Jordan_Environment_Policies_and_Engagemt.pdf (Accessed 5 October 2020).

Crawshaw, P., and Smith, J. (2009) Men's health: practice, policy, research and theory. Critical Public Health 19(3): 261-267. https://doi.org/10.1080/09581590903302071

Crenshaw, K. (1989) Demarginalizing the intersection of race and sex: a black feminist critique of antidiscrimination doctrine, feminist theory and antiracist politics. University of Chicago Legal Forum 139: 139-167.

De Jong, J., Sbeity, F., Schlecht, J. et al. (2017) Young lives disrupted: gender and well-being among adolescent Syrian refugees in Lebanon. Conflict and Health 11(23). 
Devonald, M., Jones, N., Guglielmi, S., Seager, J., and Baird, S. (forthcoming) Human rights education in humanitarian settings: opportunities and challenges. Human Rights Review.

Dryden-Peterson, S. (2017) Refugee education: education for an unknowable future. Curriculum Inquiry 47(1): 14-24. DOI: 10.1080/03626784.2016.1255935

Easton-Calabria, E., and Omata, N. (2018) Panacea for the refugee crisis? Rethinking the promotion of 'self-reliance' for refugees. Third World Quarterly 39(8): 1458-1474. DOI: 10.1080/01436597.2018.1458301

Evans, R., Lo Forte, C., and McAslan Fraser, E. (2013) UNHCR's engagement with displaced youth: a global review. Geneva: UNHCR Policy Development and Evaluation Service.

Ezard, N. (2012) Substance use among populations displaced by conflict: a literature review. Disasters 36(3): 533-557.

GAGE consortium. (2019) Gender and adolescence: why understanding adolescent capabilities, change strategies and contexts matters. Second edition. London: Gender and Adolescence: Global Evidence.

Gercama, I., Jones, N., Youssef, S., Sleiman, C., and Kwaider, O. (2018) Building social cohesion in conflict affected communities: a retrospective research study with refugee and host community adolescents in Lebanon. London: Gender and Adolescence: Global Evidence.

Greene, M. C., and Kane, J. C. (2020) Substance use among refugee and conflict-affected children and adolescents. In: Song, S., and Ventevogel, P. (Eds.), Child, adolescent and family refugee mental health. Cham: Springer. https://doi.org/10.1007/978-3-030-45278-0_11

Guglielmi, S., Muz, J., Mitu, K., Ala Uddin, M., Jones, N., Baird, S., and Presler-Marshall, E. (2019) The lives they lead: exploring the capabilities of Bangladeshi and Rohingya adolescents in Cox's Bazar, Bangladesh. Policy Brief. London: Gender and Adolescence: Global Evidence.

Hankivsky, O., Grace, D., Hunting, G., Ferlatte, O., Clark, N., Fridkin, A., Giesbrecht, M., Rudrum, S., and Laviolette, T. (2012) Intersectionality-based policy analysis. In: Hankivsky, O. (Ed.), An intersectionality-based policy analysis framework. Vancouver: Institute for Intersectionality Research and Policy, 33-45.

Hart, J. (2008) Displaced children's participation in political violence: Towards greater understanding of mobilisation. Conflict, Security \& Development 8(3): 277-293. DOI: $10.1080 / 14678800802323308$

Hassan, G., Ventevogel, P., Jefee-Bahloul, H., Barkil-Oteo, A., and Kirmayer, L. (2016) Mental health and psychosocial wellbeing of Syrians affected by armed conflict. Epidemiology and Psychiatric Sciences 25(2): 129-141. DOI: 10.1017/S2045796016000044

Hooks, B. (1981) Ain't I a woman? Black women and feminism. Boston: South End Press.

Hossain, M., Zimmerman, C., Kiss, L., Kone, D., Bakayoko-Topolska, M., Manan, D., Lehmann, H., and Watts, C. (2014) Men's and women's experiences of violence and traumatic events in rural Côte d'Ivoire before, during and after a period of armed conflict. British Medical Journal 4(2): e003644. DOI: 10.1136/bmjopen-2013-003644

Howe, P. (2019) The triple nexus: A potential approach to supporting the achievement of the Sustainable Development Goals? World Development 124: 104629. doi.org/10.1016/j. worlddev.2019.104629

Huijsmans, R. (2016) Generationing development: an introduction. In: Huijsmans, R. (Ed.), Generationing development: a relational approach to children, youth and development. London: Palgrave Macmillan, 1-31.

Huijsmans, R., George, S., Gigengack, R., and Evers, S. (2014) Theorising age and generation in development: a relational approach. European Journal of Development Research 26(2): 163. DOI: $10.1057 /$ ejdr.2013.65

Hyndman, J. (2010) Introduction: the feminist politics of refugee migration. Gender, Place \& Culture 17(4): 453-459. DOI: 10.1080/0966369X.2010.485835 
Hynes, M., and Cordozo, B. L. (2000) Observations from the CDC: sexual violence against refugee women. Journal of Women's Health \& Gender-Based Medicine 9(8): 819-823. http:// doi.org/10.1089/152460900750020847

Ibrahim, S. (2006) From individual to collective capabilities: the capability approach as a conceptual framework for self-help. Journal of Human Development 7(3): 397-416. https:// doi.org/10.1080/14649880600815982

Ilcan, S., Oliver, M., and Connoy, L. (2015) Humanitarian assistance and the politics of self-reliance: Uganda's Nakivale refugee settlement. CIGI Papers 86. Ontario: Centre for International Governance Innovation. Available at: www.cigionline.org/sites/default/files/cigi_paper_ no.86.pdf

Jabbar, S., and Zaza, H. (2014) Impact of conflict in Syria on Syrian children at the Zaatari refugee camp in Jordan. Early Child Development and Care 184(9-10): 1507-1530. https:// doi.org/10.1080/03004430.2014.916074

Jones, N., Baird, S., Presler-Marshall, E., Małachowska, A., Kilburn, K., Essaid, A., Amaireh, W., Sajdi, J., Banioweda, K., Alabbadi, T., Alheiwidi, S., Ashareef, Q., Altal, S., Kharabsheh, W., Abu Taleb, H., Abu Azzam, M., and Hammad, B. A. (2019a) Adolescent well-being in Jordan: exploring gendered capabilities, contexts and change strategies. A synthesis report on GAGE Jordan baseline findings. London: Gender and Adolescence: Global Evidence.

Jones, N., Devonald, M., and Guglielmi, S. (2019b) Leave no adolescent behind: the gender- and age-specific vulnerabilities of adolescent refugees and IDPs. Policy Note. London: Gender and Adolescence: Global Evidence.

Jones, N.,Yadete, W., and Pincock, K. (2019c) Raising the visibility of IDPs: a case study of genderand age-specific vulnerabilities among Ethiopian IDP adolescents, humanitarian practice network. London: Overseas Development Institute.

Kabeer, N., and Sulaiman, M. (2015) Assessing the impact of social mobilization: Nijera Kori and the construction of collective capabilities in rural Bangladesh. Journal of Human Development and Capabilities 16(1): 47-68. https://doi.org/10.1080/19452829.2014.956707

Katz, C. (2004) Growing up global: economic restructuring and children's everyday lives. Minneapolis; London: University of Minnesota Press.

Khan, N., Shilpi, A., Sultana, R., Sarker, S., Razia, S., Roy, B., Arif, A., Ahmed, M., Saha, S., and McConachie, H. (2018) Displaced Rohingya children at high risk for mental health problems: findings from refugee camps within Bangladesh. Child: Care, Health and Development 45(1): 28-35. https://doi.org/10.1111/cch.12623

Kostelny, K. (2006) A culture based integrative approach. In: Boothby, N., Strang, A., and Wessels, M. (Eds.), A life turned upside down: social ecological approaches to children in war zones. Bloomfield, CT: Kumarian Press.

Lenner, K., and Turner, L. (2018) Learning from the Jordan compact. Forced Migration Review 23.

Ludwig, B. (2016) 'Wiping the refugee dust from my feet': advantages and burdens of refugee status and the refugee label. International Migration 54(1): 5-18.

Macklin, A. (2008) Legal aspects of conflict-induced migration by women. Reproductive Health Matters 16(31): 22-32.

McLean, L., and Modi, A. (2016) 'Empowerment' of adolescent girls and young women in Kinshasa: research about girls, by girls. Gender \& Development 24(3): 475-491. 10.1080/13552074.2016.1239777

Mikhael, D., and Norman, J. (2018) Refugee youth, unemployment and extremism: countering the myth. Forced Migration Review 57: 57-58.

Nussbaum, M. (2011) Creating capabilities: the human development approach. Cambridge, MA: The Belknap Press of Harvard University Press. 
Nygren, A., and Wayessa, G. (2018) At the intersections of multiple marginalisations: displacements and environmental justice in Mexico and Ethiopia. Environmental Sociology 4(1): 148-161. DOI: 10.1080/23251042.2017.1419418

Odwe, G., Undie, C. C., and Obare, F. (2018) Attitudes towards help-seeking for sexual and gender-based violence in humanitarian settings: the case of Rwamwanja refugee settlement scheme in Uganda. BMC International Health and Human Rights 18(1): 15. https:// doi.org/10.1186/s12914-018-0154-6

O'Neil, T., Fleury, A., and Foresti, M. (2016) Women on the move: migration, gender equality and the 2030 Agenda for Sustainable Development. Briefing paper. London: ODI.

Patton, G. C., Coffey, C., Cappa, C., Currie, D., Riley, L., Gore, F., Degenhardt, L., Richardson, D., Astone, N., Sangowawa, A. O., Mokdad, A., and Ferguson, J. (2012) Health of the world's adolescents: a synthesis of internationally comparable data. The Lancet 379(9826): 1665-1675. https://doi.org/10.1016/S0140-6736(12)60203-7

Prout, A., and James, A. (1990) A new paradigm for the sociology of childhood? Provenance, promise and problems. In: James, A. and Prout, A. (Eds.), Constructing and reconstructing childhood. London, UK: Falmer, 7-33.

Qvortrup, J., Bardy, M., Sgritta, G., and Wintersberger, H. (1994) Childhood matters: Social theory, practice and politics. Ashgate: Avebury.

Reynolds, P., Nieuwenhuys, O., and Hanson, K. (2006) Refractions of children's rights in development practice: a view from anthropology. Childhood 13(3): 291-302. https://doi. org/10.1177/0907568206067476

Rosen, D. (2006) Child soldiers, international humanitarian law, and the globalization of childhood. American Anthropologist 109(2): 296-306. DOI: 10.1525/AA.2007.109.2.296

Sen, A. K. (2004) Capabilities, lists, and public reason: continuing the conversation. Feminist Economics 10(3): 77-80. https://doi.org/10.1080/1354570042000315163

Sheehan, P., Sweeny, K., Rasmussen, B., Wils, A., Friedman, H. S., Mahon, J., Patton, G. C., Sawyer, S. M., Howard, E., Symons, J., Stenberg, K., Chalasani, S., Maharaj, N., Reavley, N., Shi, H., Fridman, M., Welsh, A., Nsofor, E., and Laski, L. (2017) Building the foundations for sustainable development: a case for global investment in the capabilities of adolescents. The Lancet 390(10104): 1792-1806. https://doi.org/10.1016/S0140-6736(17)30872-3

Smith, A. (2014) Contemporary challenges for education in conflict affected countries. Journal of International and Comparative Education 3(1): 113-125.

Sommer, M., Muñoz-Laboy, M., Williams, A., Mayevskaya,Y., Falb, K., Abdella, G., and Stark, L. (2018) How gender norms are reinforced through violence against adolescent girls in two conflict-affected populations. Child Abuse \& Neglect 79: 154-163. DOI: 0.1016/j. chiabu.2018.02.002

Steinberg, L. (2015) Age of opportunity: Lessons from the new science of adolescence. New York: Eamon Dolan/Mariner Books.

Tisdall, E. K. M., and Punch, S. (2012) Not so 'new'? Looking critically at childhood studies. Children's Geographies 10(3): 249-264. https://doi.org/10.1080/14733285.2012.693376

United Nations. (2015) Transforming our world: the 2030 agenda for sustainable development. New York: UN. Available at: https://sdgs.un.org/2030agenda

UN DESA. (2017) International migration report 2017. New York: UN DESA. Available at: www.un.org/en/development/desa/population/migration/publications/ migrationreport/docs/MigrationReport2017.pdf

UNESCO. (2019) The intersections between education, migration and displacement are not genderneutral. Global Education Monitoring Report. Paris: UNESCO.

UNHCR. (2018) Global trends: forced displacement in 2018. Geneva: UNHCR. Available at: www.unhcr.org/5d08d7ee7.pdf 
UNHCR. (2019a) The global compact on refugees: indicator framework. Geneva: UNHCR.

UNHCR. (2019b) Stepping up: refugee education in crisis. Geneva: UNHCR.

UNHCR. (2019c) Global refugee forum pledges collective action for better refugee inclusion, education, jobs. Press Release, 18 December 2019. Available at: www.unhcr.org/ uk/news/press/2019/12/5dfa56b54/global-refugee-forum-pledges-collective-actionbetter-refugee-inclusion.html (Accessed 22 October 2020).

UNICEF. (2017) Education uprooted. New York: UNICEF.

UNICEF. (2019) Every child learns: UNICEF education strategy 2019-2030. New York: UNICEF. Available at: https://www.unicef.org/media/59856/file/UNICEF-educationstrategy-2019-2030.pdf

UNMGCY (United Nations Major Group for Children and Youth). (2019) Global youth caucus on SDG 16. United Nations. Available at: www.unmgcy.org/sdg-16-publication (Accessed 5 October 2020).

UNOCHA. (2017). The new way of working. Update. Available at: https://www.unocha.org/ story/new-way-working

Viner, R., Ross, D., Hardy, R., Kuh, D., Power, C., Johnson, A., Wellings, K., McCambridge, J., Cole, T., Kelly, Y., and Batty, G. D. (2015) Life course epidemiology: recognising the importance of adolescence. Journal of Epidemiology and Community Health 69(8): 719-720. http://dx.doi.org/10.1136/jech-2014-205300

Wanjiru, J. (2018) Inclusive education for internally displaced children in Kenya: children's perceptions of their learning and development needs in post-conflict schooling. International Journal of Child Care and Education Policy 12(7). https://doi.org/10.1186/ s40723-018-0046-1

Watson, C. (2015) Understanding changing social norms and practices around girls' education and marriage: lessons learned and emerging issues from year 2 of a multicountry field study. London: ODI.

White, S. (1996) Depoliticising development: the uses and abuses of participation. Development in Practice 6(1): 6-15. https://doi.org/10.1080/0961452961000157564

Williams, T. P., Chopra, V., and Chikanya, S. R. (2018) 'It isn't that we're prostitutes': child protection and sexual exploitation of adolescent girls within and beyond refugee camps in Rwanda. Child Abuse \& Neglect 86: 158-166. https://doi.org/10.1016/j. chiabu.2018.09.015

Zwier-Marongedza, J. (2020) Supporting Girls' Agency in the Covid-19 response for education across fragile contexts. Presentation by Program Quality and Development Director, World Vision, Zimbabwe and Program Director of Improving Gender Attitudes, Transition and Education Outcomes (IGATE), Zimbabwe. (Webinar). Available at: www.youtube.com/ watch?v=O2WQMNGf2ZA\&feature=youtu.be 